\title{
Interpersonal interactions, job demands and work-related outcomes in pharmacy
}

\author{
Caroline A. Gaither ${ }^{a}$ and Anagha Nadkarni ${ }^{b}$

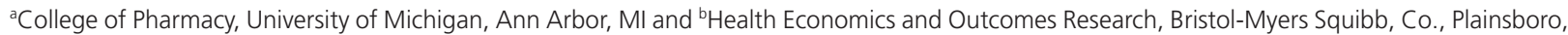 \\ NJ, USA
}

\section{Keywords}

interpersonal interactions; job demands;

pharmacists; resources; work-related outcomes

\section{Correspondence \\ Dr Anagha Nadkarni, Health Economics and Outcomes Research, Bristol-Myers Squibb, Co., 777 Scudders Mill Road, Plainsboro, NJ 08536, USA. \\ E-mail: anaghan@umich.edu}

Received April 2, 2010

Accepted September 5, 2011

doi: 10.1111/j.2042-7174.2011.00165.x

\begin{abstract}
Objectives The objective of this study was to examine the interaction between job demands of pharmacists and resources in the form of interpersonal interactions and its association with work-related outcomes such as organizational and professional commitment, job burnout, professional identity and job satisfaction. The job demands-resources (JD-R) model served as the theoretical framework.

Methods Subjects for the study were drawn from the Pharmacy Manpower Project Database $(n=1874)$. A 14-page mail-in survey measured hospital pharmacists' responses on the frequency of occurrence of various job-related scenarios as well as work-related outcomes. The study design was a $2 \times 2$ factorial design. Responses were collected on a Likert scale. Descriptive statistics, reliability analyses and correlational and multiple regression analyses were conducted using SPSS version 17 (SPSS, Chicago, IL, USA).

Key findings The 566 pharmacists (30\% response rate) who responded to the survey indicated that high-demand/pleasant encounters and low-demand/pleasant encounters occurred more frequently in the workplace. The strongest correlations were found between high-demand/unpleasant encounters and frequency and intensity of emotional exhaustion. Multiple regression analyses indicated that when controlling for demographic factors high-demand/unpleasant encounters were negatively related to affective organizational commitment and positively related to frequency and intensity of emotional exhaustion. Low-demand/pleasant encounters were positively related to frequency and intensity of personal accomplishment. Lowdemand/unpleasant encounters were significantly and negatively related to professional commitment, job satisfaction and frequency and intensity of emotional exhaustion, while high-demand/pleasant encounters were also related to frequency and intensity of emotional exhaustion

Conclusion Support was found for the JD-R model and the proposed interaction effects. Study results suggest that adequate attention must be paid to the interplay between demands on the job and interactions with healthcare professionals to improve the quality of the pharmacist's work life. Future research should examine other types of job demands and resources.
\end{abstract}

\section{Introduction}

A disturbing trend in recent years has been pharmacist shortages in various practice settings across several countries. ${ }^{[1,2]}$ Improving pharmacists' work environment is imperative to recruiting and retaining pharmacists and enhancing the quality of their work life. ${ }^{[2]}$ To date, to the best of our knowledge, the interplay between demands on the job and job-related resources such as the quality of interactions with other healthcare professionals and its subsequent impact on work-related outcomes has not been investigated. While various stressor-strain models suggest that job demands and resources affect work-related outcomes ${ }^{[3]}$ there is no empirical evidence to date to support that theory among pharmacy 
professionals. This study is an attempt to investigate the interaction between job demands and interpersonal interactions of pharmacists and to examine its impact on organizational and professional commitment, job satisfaction, job burnout and professional identity.

\section{Interpersonal interactions}

Learning to communicate effectively and developing interpersonal skills is important in ensuring an environment that promotes quality care and improved patient outcomes. ${ }^{[4,5]}$ Healthcare teams have demonstrated tremendous potential to improve the quality and efficiency of health care, with an important aspect of such teams being communication between healthcare team members. ${ }^{[6]}$ Collaborative nursephysician relationships have been shown to improve patient outcomes. ${ }^{[4]}$ There is also evidence suggesting a relationship between the quality of nurse-physician relationship and nurse perception regarding the quality of care delivered. ${ }^{[5]}$ It might thus be reasonable to suggest that team and communication failures and unpleasant interpersonal interactions within the healthcare workplace have the potential to decrease quality and even possibly cause adverse outcomes.

In addition to safety and quality issues, interpersonal interactions and collaboration also play an important role in job satisfaction and intent to leave.$^{[5,7,8]}$ Research indicates that collaboration between the nurse and physician has a positive effect on job satisfaction. ${ }^{[9]}$ Disruptive physician behaviour has also been found to be associated with nurse job dissatisfaction. ${ }^{[8]}$ This is consistent with results from a follow-up study by Rosenstein and O'Daniel in which respondents who were nurses, physicians or hospital administrators agreed that disruptive physician behaviour may potentially lead to adverse patient outcomes (94\%), job stress (94\%) and other negative outcomes such as frustration. ${ }^{[10]}$ Different conflict-resolution styles employed to resolve conflicts with physicians have also been found to be associated with job satisfaction and job stress in nurses. ${ }^{[11]}$ An 'integrating' conflict-resolution style indicating a collegial style of communication was associated with lower levels of stress. ${ }^{[1]}$ There is also some research in the pharmacy literature that examines this. A study which focused on perceived barriers to providing cognitive services by pharmacists found that job satisfaction of pharmacists and the amount of interaction with physicians was significantly positively correlated. ${ }^{[12]}$ Further, satisfaction with physician interaction was significantly correlated with both job satisfaction and career satisfaction. ${ }^{[12]}$ Thus, there is evidence in the literature that the interactions between healthcare professionals impact work-related outcomes.

\section{Job demands}

Healthcare professionals including pharmacists experience highly taxing and demanding situations at work. ${ }^{[13]}$ Within the field of pharmacy, the numbers of prescriptions dispensed continues to increase and when combined with the shortage of pharmacists this contributes to the taxing demands felt by currently practising pharmacists. ${ }^{[2,14]}$

Studies which focus on healthcare professionals have found that job demands such as the workload and role conflict affect work-related outcomes such as job satisfaction and burnout. ${ }^{[15]}$ Importantly and specific to the field of pharmacy, studies have demonstrated the impact of job demands on work-related outcomes such as intention to leave. ${ }^{[16]}$

Job stress is the negative psychological response to job demands in the work place. ${ }^{[17]}$ Given the demands of the job in the field of pharmacy it is not surprising that pharmacists in various practice settings report that they experience job stress. ${ }^{[17-22]}$ Studies have consistently linked job stress and job-stress dimensions such as lack of job control with various negative outcomes for pharmacists, including job dissatisfaction, ${ }^{[18-20]}$ a decrease in career commitment, ${ }^{[19]}$ burnout ${ }^{[21,22]}$ and job turnover. ${ }^{[23]}$ One of the reasons for pharmacists leaving their jobs has been found to be stress, with the reported stress levels in one study on pharmacist turnover increasing significantly between the period 1983-1987 and 1993-1997. ${ }^{[23]}$ Further, job stress resulting from hectic work schedules, job discontent, adverse work conditions and interactions with other healthcare professionals has been found to be significantly correlated with burnout experienced by pharmacists. ${ }^{[21]}$ As illustrated, demands of the job and the accompanying stress have many consequences with respect to job satisfaction, career and professional commitment, intent to leave and burnout. ${ }^{[15,16,18-22]}$

\section{Theoretical background}

The job demands-resources (JD-R) model suggests that both job demands and job resources are associated with burnout. ${ }^{[3]}$ Job demands refer to physical, social or organizational factors of the job that require a person to exert physical or mental effort. This expenditure of effort is related to physiological or psychological costs such as exhaustion or burnout. Job resources refer to those physical, psychological, social or organizational factors that help the person perform better at the job, diminish the demands of the job or stimulate growth. A lack of job resources can lead to disengagement from work.

The JD-R model posits that burnout develops through two pathways. In the first pathway, taxing job demands can lead to exhaustion over time. The second pathway is due to a lack of resources which makes it difficult to meet demands on the job and this ultimately leads to disengagement. Exhaustion and disengagement are components of burnout as defined by Maslach and Jackson. ${ }^{[24]}$

Thus, the JD-R model categorizes working conditions into job demands and resources and describes the process by which working conditions ultimately lead to outcomes such 
as burnout. The focus of our study was to test the interaction between the working conditions specified in the JD-R model and examine the impact of this interaction on work-related outcomes. As a result, conceptually, the JD-R model provided a sound theoretical framework for our study. Our study focused on several physical, social and organizational working conditions or job demands of a pharmacist. In addition, we also focused on interpersonal interactions. Interpersonal interactions have been shown to impact patient outcomes $^{[4]}$ and the perception regarding the quality of care delivered by nurses. ${ }^{[5]}$ This suggests that interpersonal interactions can determine how a person performs at work. In the JD-R model, resources are defined as factors that help determine how a person performs at work and accordingly, for the purpose of our study, we conceptualized interpersonal interactions as being a type of resource.

The JD-R model proposes that demands and resources differentially impact outcomes such as exhaustion. This study investigates the interaction between job demands and resources and its relationship with burnout and other related constructs such as organizational and professional commitment, job satisfaction and professional identity.

The study hypothesis is that high demands and a lack of resources can have a negative impact on work-related outcomes such as job satisfaction or commitment. It is also hypothesized that situations in which an interaction occurs between a high demand and availability of resources or low demand and the lack of resources are not negatively associated with work-related outcomes. It is thus suggested that the presence of one counterbalances the impact of the other.

\section{Research objective}

The objective of this study was to examine the association between job demands (high/low) and encounters (pleasant/ unpleasant) with work-related outcomes such as organizational and professional commitment, job satisfaction, burnout and professional identity.

\section{Hypotheses}

Hypothesis 1 was that low-demand/pleasant encounters are positively associated with organizational commitment, professional commitment, job satisfaction, professional identity and personal accomplishment and negatively associated with emotional exhaustion and depersonalization. Hypothesis 2 was that high-demand/unpleasant encounters are negatively associated with organizational commitment, professional commitment, job satisfaction, professional identity and personal accomplishment and positively associated with emotional exhaustion and depersonalization. Hypothesis 3 was that high-demand/pleasant encounters or low-demand/ unpleasant encounters are not associated with organizational commitment, professional commitment, job satisfaction, professional identity personal accomplishment, emotional exhaustion or depersonalization.

\section{Materials and methods}

\section{Study design}

Subjects were drawn from the Pharmacy Manpower Project Database which had a list of 3168 hospital-based pharmacists who graduated prior to 1993. This database was used because it could identify pharmacists practising in hospital pharmacies. Of those listed in the database, 1874 addresses were found to be current and these pharmacists formed the sample for the study. The study protocol was reviewed by the University of Michigan's Institutional Review Board and received approval.

\section{Survey design}

Data in this cross-sectional study were collected using a 14-page questionnaire. The questionnaire contained one of four hospital-based scenarios in which the pharmacist is faced with either a high- or a low-demand situation and either an unpleasant or a pleasant physician encounter. These scenarios formed the stressor in the study and are described in Appendix A.

The frequency with which a particular scenario occurred was the primary independent variable in the study. After being presented with one of the four scenario described previously, respondents were asked 'How often have you experienced a situation similar to that above?' The response format for this item included an eight-point Likert-type scale with the following response categories: $0=$ never, $1=$ once or twice over the past few years, $2=$ a few times a year, $3=$ once $a$ month or less, $4=\mathrm{a}$ few times a month, $5=$ once a week, $6=\mathrm{a}$ few times a week and 7 = every day.

Responses pertaining to the domains of organizational commitment, professional commitment, job satisfaction, burnout and professional identity were measured using either five- or seven-point Likert-type scales previously used in literature.

Organizational commitment was conceptualized as a multidimensional construct consisting of affective commitment, continuance commitment and normative commitment. Affective commitment is an employee's emotional attachment to, identification with and involvement in the organization. ${ }^{[25]}$ Continuance commitment is defined as the perceived costs associated with leaving the organization. ${ }^{[25]}$ Normative commitment is defined as the perceived obligation to remain with the organization. ${ }^{[26]}$ Affective commitment, continuance commitment and normative commitment were each measured using eight items and thus there were 24 items that 
measured organizational commitment. The responses to these 24 items were measured using a seven-point Likert-type scale with choices ranging from $1=$ strongly disagree to $7=$ strongly agree. ${ }^{[27]}$

Professional commitment was defined as one's attitude towards one's profession or vocation. ${ }^{[28]}$ It was measured using seven items on a five-point Likert-type scale with $1=$ strongly disagree to $5=$ strongly agree. ${ }^{[29]}$ Job satisfaction is the extent to which people like or dislike their jobs. The job satisfaction score was measured using three items on a five-point Likert-type scale with $1=$ strongly disagree to $5=$ strongly agree. ${ }^{[30]}$

Professional identity for the purpose of this study was adapted from Bergami and Bagozzi's definition of organizational identity. ${ }^{[31]}$ Professional identity is defined as the extent to which the pharmacist's self-image overlaps with the profession of pharmacy. Professional identity was measured using a single item with a Likert-type response format with responses ranging from $1=$ to no extent at all and $7=$ to a great extent.

Burnout is a syndrome of emotional exhaustion and cynicism that occurs frequently among individuals who do 'people work' of some kind. ${ }^{[32]}$ It is a multidimensional construct consisting of emotional exhaustion, depersonalization and personal accomplishment. Emotional exhaustion is the feeling of being emotionally overextended and exhausted, depersonalization is a negative and dehumanizing response towards people who are the recipient of one's services and a decrease in personal accomplishment refers to one's feelings of incompetence in one's work with people resulting from repeated failed attempts to generate positive results. Burnout was measured using the prevalidated and reliable Maslach Burnout Inventory with responses measured on a six- or seven-point Likert-type scale. ${ }^{[32]}$ The burnout inventory contains 22 items which elicit responses on how often and how strong specific feelings relating to the domains of emotional exhaustion, depersonalization and personal accomplishment occur. It was measured using a response format covering never to every day (frequency) and very mild to very strong (intensity).

Demographic information such as age, gender, race, education level, population of town worked, position and yearly income were also elicited from the respondents. The questionnaire was pretested on a sample of 50 pharmacists from the study population. Since the pretest did not yield any significant changes to the final survey, the responses from the pretest subjects were included in the final survey analysis.

\section{Data collection and analyses}

Subjects for this study were contacted up to three times. Questionnaires were mailed to pharmacists from the Pharmacy Manpower Project Database whose addresses were found to be current. This was followed by a thank you postcard after 2 weeks. Subsequently, a second mailing was sent to non-respondents. Data were analysed using SPSS version 17 (SPSS, Chicago, IL, USA). Descriptive statistics (frequencies, means and standard deviations) and a reliability analysis (Cronbach's alpha) were calculated. Non-parametric statistical tests were used to determine significant associations. Based on the results from the non-parametric statistics, if the association between frequency of scenario occurrence and the work-related outcomes was found to be significant, multiple regression analyses were used to test the hypotheses. A predetermined significance level of 0.05 was used for all analyses.

\section{Results}

A total of 566 completed surveys was obtained, resulting in a response rate of $30.2 \%$. The response rates per scenario were as follows: high-demand/pleasant encounter 29.4\% ( $n=138)$, high-demand/unpleasant encounter $26.0 \quad(n=$ $122)$, low-demand/pleasant encounter $31.8 \%(n=149)$ and low-demand/unpleasant encounter 33.5\% $(n=157)$. The average age of the respondents was 48.3 years (SD 9.6 years) and they worked $37.9 \mathrm{~h}(11.3 \mathrm{~h})$ weekly. As shown in Table 1 $51.3 \%$ of the respondents were male, $82.5 \%$ were white and about $94 \%$ had a Bachelor of Science in pharmacy degree. A majority of the respondents worked in places with a population of 500000 or more and $46.8 \%$ identified themselves as general staff. With respect to salary, the majority of pharmacists earned more than US\$59 999 annually.

\section{Non-response bias}

Since no demographic data were available from the Pharmacy Manpower Project Database on the 1308 non-respondents to our survey, non-response bias was determined by dividing the surveys obtained into two groups: those who responded to the first mailing and those who responded to the second mailing of the survey and comparing them by demographic information. This approach is based on the assumption that subjects who respond less readily are more like nonrespondents and is commonly used when no demographic information is available on subjects who do not respond. ${ }^{[33]}$ Chi-square analysis indicated that there were no significant differences between the two groups with respect to gender, race, education, population of town worked, salary earned or any of the work-related outcomes.

\section{Frequency of scenario occurrence}

Low-demand/pleasant encounters and high-demand/ pleasant encounters occurred more frequently than either 
Table 1 Demographic characteristics

\begin{tabular}{|c|c|}
\hline Variable & $\%(n)$ \\
\hline \multicolumn{2}{|l|}{ Sex } \\
\hline Male & $51.3(290)$ \\
\hline Female & $48.7(276)$ \\
\hline \multicolumn{2}{|l|}{ Ethnicity } \\
\hline White & $80.2(467)$ \\
\hline Non-White & $19.8(99)$ \\
\hline \multicolumn{2}{|l|}{ Highest previous degree } \\
\hline BS Pharmacy & $93.8(531)$ \\
\hline PharmD as first degree & $2.8(16)$ \\
\hline PharmD, post BS & $9.5(54)$ \\
\hline Residency/Fellowship & $7.1(40)$ \\
\hline MS & $9.9(56)$ \\
\hline MBA & $4.1(23)$ \\
\hline Other ${ }^{a}$ & $10.6(60)$ \\
\hline \multicolumn{2}{|c|}{ Population of town where the pharmacist is working } \\
\hline $2499-9999$ & $9.3(53)$ \\
\hline $10000-49999$ & $17.9(101)$ \\
\hline $50000-99999$ & $16.6(94)$ \\
\hline $100000-499999$ & $23.0(130)$ \\
\hline 500000 or more & $33.2(188)$ \\
\hline \multicolumn{2}{|l|}{ Position } \\
\hline Management & $28.8(163)$ \\
\hline General staff & $46.8(265)$ \\
\hline Clinical staff & $15.6(88)$ \\
\hline Other $^{\text {b }}$ & $6.6(37)$ \\
\hline \multicolumn{2}{|l|}{ Salary (US\$) } \\
\hline$\$ 0-\$ 59999$ & $36.8(208)$ \\
\hline$\$ 60000-\$ 69999$ & $37.1(210)$ \\
\hline$\$ 70000$ or more & $26.1(148)$ \\
\hline
\end{tabular}

BS = Bachelor of Science; PharmD = Doctor of Pharmacy; MS = Master of Science; MBA = Masters of Business Administration.

${ }^{\mathrm{a}}$ Other $=\mathrm{PhD}$ or other certification

${ }^{b}$ Other $=$ health facility consultant or clinical coordinator.

Table 2 Frequency with which each scenario occurred

\begin{tabular}{|c|c|c|c|}
\hline \multirow[b]{2}{*}{ Scenario } & \multirow[b]{2}{*}{ Median } & \multicolumn{2}{|c|}{ Percentile } \\
\hline & & 25th & 50th \\
\hline High-demand/pleasant encounter & 3.0 & 2.0 & 5.0 \\
\hline High-demand/unpleasant encounter & 1.0 & 1.0 & 2.0 \\
\hline Low-demand/pleasant encounter & 4.0 & 2.0 & 5.0 \\
\hline Low-demand/unpleasant encounter & 1.0 & 1.0 & 2.0 \\
\hline
\end{tabular}

high or low-demand/unpleasant encounters. A summary of the frequency with which each scenario occurred is given in Table 2.

\section{Overall means for work-related outcomes and scale reliability analysis}

Overall the means for the three dimensions of organizational commitment suggest that the pharmacists in the study scored their level of organizational commitment at the
Table 3 Overall means for work-related outcomes

\begin{tabular}{lll}
\hline Work-related outcomes & Mean (SD) & $\begin{array}{l}\text { Cronbach's } \\
\text { Alpha }\end{array}$ \\
\hline Affective commitment $^{\mathrm{a}}$ & $4.29(1.09)$ & 0.73 \\
Continuance commitment $^{\mathrm{a}}$ & $3.72(1.33)$ & 0.80 \\
Normative commitment $^{\mathrm{a}}$ & $3.65(0.97)$ & 0.70 \\
Professional commitment $^{\mathrm{b}}$ & $3.16(0.94)$ & 0.81 \\
Job satisfaction $^{\mathrm{b}}$ & $3.72(0.85)$ & 0.80 \\
Frequency of emotional exhaustion $^{\mathrm{c}}$ & $2.64(1.33)$ & 0.90 \\
Intensity of emotional exhaustion $^{\mathrm{d}}$ & $3.35(1.49)$ & 0.89 \\
Frequency of personal accomplishment $^{\mathrm{c}}$ & $4.50(0.93)$ & 0.76 \\
Intensity of personal accomplishment $^{\mathrm{d}}$ & $4.84(1.01)$ & 0.81 \\
Frequency of depersonalization $^{\mathrm{c}}$ & $1.49(1.20)$ & 0.76 \\
Intensity of depersonalization $^{\mathrm{d}}$ & $1.88(1.84)$ & 0.78 \\
Professional identity $^{\mathrm{a}}$ & $4.60(1.42)$ & - \\
\hline
\end{tabular}

a1-7-point scale; ${ }^{\mathrm{a}} 1-5$-point scale; ${ }^{\mathrm{c}} 0-6$-point scale; ${ }^{\mathrm{d}} 0$-7-point scale.

higher end of the scales, indicating a moderately high level of organizational commitment. Pharmacists also scored a mean of $3.72(0.85)$ on the job satisfaction scale indicating that, overall, the respondents were satisfied with their jobs. The means for the Maslach Burnout Inventory also suggest that respondents reported being emotionally exhausted. However, the responses to the personal accomplishment scale suggest that the respondents did feel a sense of personal accomplishment with their work and did not exhibit feelings of depersonalization towards people they dealt with in their jobs. Respondents also exhibited a moderate level of professional commitment and professional identity with their chosen careers. The Cronbach's alpha for the summated scales were all higher than 0.70 , which indicates good consistency in measurement. A detailed summary of means and reliability analysis for the work-related outcomes is presented in Table 3.

\section{Associations between demographic factors and frequency of scenario occurrence}

Very few differences were found across the demographic variables and frequency of scenario occurrence. Hours worked per week were positively correlated with low-demand/ pleasant encounters (Spearman's rho $=0.22, P<0.001$ ). Men (median $=1.00)$ were less likely to encounter high demands and unpleasant encounters than women $($ median $=2.00)$ (Mann-Whitney $U=1082.5 ; 25$ th percentile $=1.0$, 75th percentile $=2.0 ; Z=-3.81, \quad P<0.001)$ and clinical staff (median $=4.00)$ were more likely than management $($ median $=2.00)$ or general staff $($ median $=3.00)$ to experience high-demand/pleasant encounters (Kruskal-Wallis; 25 th percentile $=2.00,75$ th percentile $=5.00 ; \chi^{2}=6.2$, d.f. $=$ $2, P<0.04)$. 


\section{Associations between frequency of scenario occurrence and work-related outcomes}

Spearman rank correlations were computed to evaluate the relationship between the frequency with which a particular scenario occurred and work-related outcomes (Table 4). The largest correlations were found for the high-demand/ unpleasant encounter and frequency and intensity of emotional exhaustion. Experiencing this scenario more frequently was negatively associated with affective commitment and frequency of personal accomplishment and positively correlated with continuance commitment, frequency and intensity of emotional exhaustion, and frequency and intensity of depersonalization. High-demand/pleasant encounters were significantly correlated with frequency and intensity of emotional exhaustion and personal accomplishment. Lowdemand/pleasant encounters were significantly correlated with professional commitment and identity, and frequency and intensity of personal accomplishment, while lowdemand/unpleasant encounters were significantly related to affective organizational and professional commitments, job satisfaction and frequency and intensity of emotional exhaustion.

\section{Tests of study hypotheses}

To determine whether the above relationships were still significant when demographic variables were held constant, multiple linear regression analyses were performed. The regression residuals were checked and found to be normally distributed. The results of these analyses are shown in Table 5.

Hypothesis 1: complete support for hypothesis 1 was found for frequency and intensity of personal accomplishment. The more often the pharmacist experienced low-demand/pleasant encounters, the greater feelings of personal accomplishment. Partial support was found for the effects of frequency of scenario occurrence on professional identity. When demographic variables were added to the regression equation, the relationship between frequency of scenario occurrence and professional identity almost reached significance (unstandardized beta $=0.14, \mathrm{SE}=0.07$, standardized beta $=0.20, P=0.06)$.

Hypothesis 2: complete support for hypothesis 2 was found for affective organizational commitment and frequency and intensity of emotional exhaustion. The occurrence of high-demand/unpleasant encounters had negative effects on affective commitment even with the demographic variables held constant. Occurrence of this scenario was associated with a higher frequency and intensity of emotional exhaustion. These relationships continued to be significant even when demographic variables were held constant. Hypothesis 3: the non-effects of high-demand/pleasant encounters were supported for most of the work-related outcomes. The effects of this scenario were either not significant at all or were only significant for frequency and intensity of emotional exhaustion; and intensity of personal accomplishment was only strongly significant when the demographic variables were not included.

Several significant effects were found for low-demand/ unpleasant encounters. When occurrence of this scenario was regressed on professional commitment, job satisfaction, and frequency and intensity of emotional exhaustion, significant effects were found. Negative effects of this scenario were found for professional commitment and job satisfaction and positive effects were noted for frequency and intensity of emotional exhaustion. These effects were still significant when demographic variables were taken into account.

Table 4 Spearman rank correlations of the associations between frequency of scenario occurrence and the work-related outcomes

\begin{tabular}{|c|c|c|c|c|}
\hline \multirow[b]{2}{*}{ Work-related outcomes } & \multicolumn{4}{|l|}{ Scenario } \\
\hline & $\begin{array}{l}\text { High-demand/ } \\
\text { pleasant } \\
\text { encounter }\end{array}$ & $\begin{array}{l}\text { High-demand/ } \\
\text { unpleasant } \\
\text { encounter }\end{array}$ & $\begin{array}{l}\text { Low-demand/ } \\
\text { pleasant } \\
\text { encounter }\end{array}$ & $\begin{array}{l}\text { Low-demand/ } \\
\text { unpleasant } \\
\text { encounter }\end{array}$ \\
\hline Affective commitment & -0.12 & $-0.23 * *$ & 0.02 & $-0.10^{\star}$ \\
\hline Continuance commitment & 0.06 & $0.19^{*}$ & -0.02 & -0.07 \\
\hline Normative commitment & -0.03 & -0.14 & 0.04 & 0.08 \\
\hline Professional commitment & -0.12 & -0.16 & $0.18^{*}$ & $-0.18^{*}$ \\
\hline Job satisfaction & -0.09 & -0.07 & 0.10 & $-0.15^{*}$ \\
\hline Frequency of emotional exhaustion & $0.27 * *$ & $0.35^{* *}$ & 0.06 & $0.24 * *$ \\
\hline Intensity of emotional exhaustion & $0.23^{* *}$ & $0.32^{* *}$ & 0.05 & $0.16^{\star}$ \\
\hline Frequency of personal accomplishment & $0.19 *$ & $-0.20 *$ & $0.29 * *$ & 0.01 \\
\hline Intensity of personal accomplishment & $0.22 * *$ & -0.09 & $0.22 * *$ & 0.04 \\
\hline Frequency of depersonalization & 0.03 & $0.24 * *$ & 0.09 & 0.11 \\
\hline Intensity of depersonalization & -0.03 & $0.24 * *$ & 0.11 & 0.11 \\
\hline Professional identity & -0.07 & -0.07 & $0.18^{*}$ & 0.06 \\
\hline
\end{tabular}


Table 5 Regression results of frequency of scenario occurrence on work-related outcomes

\begin{tabular}{|c|c|c|c|c|}
\hline \multirow{2}{*}{ Work-related outcome } & \multirow{2}{*}{$\begin{array}{l}\text { Tests of Hypothesis } 3 \\
\text { High-demand/pleasant } \\
\text { encounter } \\
\text { Unstd B (standard error) }\end{array}$} & \multirow{2}{*}{$\begin{array}{l}\text { Test of Hypothesis } 2 \\
\text { High-demand/unpleasant } \\
\text { encounter } \\
\text { Unstd B (standard error) } \\
\text { Std B }\end{array}$} & \multirow{2}{*}{$\begin{array}{l}\text { Test of Hypothesis } 1 \\
\text { Low-demand/pleasant } \\
\text { encounter } \\
\text { Unstd B (standard error) }\end{array}$} & \multirow{2}{*}{$\begin{array}{l}\text { Test of Hypothesis } 3 \\
\text { Low-demand/unpleasant } \\
\text { encounter } \\
\text { Unstd B (standard error) } \\
\text { Std B }\end{array}$} \\
\hline & & & & \\
\hline \multicolumn{5}{|l|}{ Affective organizational commitment } \\
\hline Frequency of scenario occurrence & & $\begin{array}{l}-1.16(0.44)-0.25^{* *} \\
r^{2}=0.05^{* *}\end{array}$ & & $\begin{array}{l}-1.01(0.59)-0.15 \\
r^{2}=0.02\end{array}$ \\
\hline Frequency of scenario occurrence ${ }^{a}$ & & $\begin{array}{l}-1.13(0.41)-0.24^{* *} \\
r^{2}=0.21^{* * *}\end{array}$ & & $\begin{array}{l}-1.01(0.60)-0.15 \\
r^{2}=0.06\end{array}$ \\
\hline \multicolumn{5}{|l|}{ Continuance commitment } \\
\hline Frequency of scenario occurrence & & $\begin{array}{l}0.77(0.65) 0.12 \\
r^{2}=0.00\end{array}$ & & \\
\hline Frequency of scenario occurrence ${ }^{a}$ & & $\begin{array}{l}0.48(0.66) 0.07 \\
r^{2}=0.01\end{array}$ & & \\
\hline \multicolumn{5}{|l|}{ Professional commitment } \\
\hline Frequency of scenario occurrence & & & $\begin{array}{l}0.48(0.29) 0.15 \\
r^{2}=0.01\end{array}$ & $\begin{array}{l}-1.33(0.41)-0.28^{* *} \\
r^{2}=0.07^{* *}\end{array}$ \\
\hline Frequency of scenario occurrence ${ }^{a}$ & & & $\begin{array}{l}0.35(0.30) 0.11 \\
r^{2}=0.01\end{array}$ & $\begin{array}{l}-1.23(0.42)-0.26^{* *} \\
r^{2}=0.11^{* *}\end{array}$ \\
\hline \multicolumn{5}{|l|}{ Job satisfaction } \\
\hline Frequency of scenario occurrence & & & & $\begin{array}{l}-0.31(0.17)-0.15 \\
r^{2}=0.02\end{array}$ \\
\hline Frequency of scenario occurrence ${ }^{a}$ & & & & $\begin{array}{l}-0.32(0.17)-0.16^{*} \\
r^{2}=0.14^{* * *}\end{array}$ \\
\hline \multicolumn{5}{|l|}{ Frequency of emotional exhaustion } \\
\hline Frequency of scenario occurrence & $\begin{array}{l}1.47(0.54) 0.25^{* *} \\
r^{2}=0.05^{* *}\end{array}$ & $\begin{array}{l}2.27(0.73) 0.29^{* *} \\
r^{2}=0.08^{* *}\end{array}$ & & $\begin{array}{l}2.28(0.73) 0.27^{* *} \\
r^{2}=0.06^{* *}\end{array}$ \\
\hline Frequency of scenario occurrence ${ }^{a}$ & $\begin{array}{l}1.49(0.57) 0.25^{* *} \\
r^{2}=0.09^{*}\end{array}$ & $\begin{array}{l}2.25(0.74) 0.29^{* *} \\
r^{2}=0.08^{*}\end{array}$ & & $\begin{array}{l}2.46(0.73) 0.29 * * * \\
r^{2}=0.12^{* *}\end{array}$ \\
\hline \multicolumn{5}{|l|}{ Intensity of emotional exhaustion } \\
\hline Frequency of scenario occurrence & $\begin{array}{l}1.43(0.60) 0.22^{*} \\
r^{2}=0.04^{*}\end{array}$ & $\begin{array}{l}2.41(0.81) 0.28^{* *} \\
r^{2}=0.07^{* *}\end{array}$ & & $\begin{array}{l}1.43(0.83) 0.15 \\
r^{2}=0.02\end{array}$ \\
\hline Frequency of scenario occurrence ${ }^{a}$ & $\begin{array}{l}1.41(0.63) 0.22^{*} \\
r^{2}=0.09^{*}\end{array}$ & $\begin{array}{l}2.50(0.82) 0.30^{* *} \\
r^{2}=0.07^{*}\end{array}$ & & $\begin{array}{l}1.81(0.83) 0.19^{*} \\
r^{2}=0.09 *\end{array}$ \\
\hline \multicolumn{5}{|l|}{ Frequency of personal accomplishment } \\
\hline Frequency of scenario occurrence & $\begin{array}{l}0.65(0.34) 0.18 \\
r^{2}=0.02\end{array}$ & $\begin{array}{l}-0.55(0.44)-0.12 \\
r^{2}=0.01\end{array}$ & $\begin{array}{l}1.33(0.33) 0.35^{* * *} \\
r^{2}=0.11^{* * *}\end{array}$ & \\
\hline Frequency of scenario occurrence ${ }^{a}$ & $\begin{array}{l}0.24(0.35) 0.07 \\
r^{2}=0.11^{* *}\end{array}$ & $\begin{array}{l}-0.61(0.44)-0.14 \\
r^{2}=0.04\end{array}$ & $\begin{array}{l}1.17(0.35) 0.30^{* * *} \\
r^{2}=0.11^{* *}\end{array}$ & \\
\hline \multicolumn{5}{|l|}{ Intensity of personal accomplishment } \\
\hline Frequency of scenario occurrence & $\begin{array}{l}0.77(0.37) 0.20^{*} \\
r^{2}=0.03^{*}\end{array}$ & & $\begin{array}{l}1.15(0.42) 0.25^{* *} \\
r^{2}=0.05^{* *}\end{array}$ & \\
\hline Frequency of scenario occurrence ${ }^{a}$ & $\begin{array}{l}0.52(0.38) 0.14 \\
r^{2}=0.10^{*}\end{array}$ & & $\begin{array}{l}0.93(0.43) 0.20^{*} \\
r^{2}=0.08^{*}\end{array}$ & \\
\hline \multicolumn{5}{|l|}{ Frequency of depersonalization } \\
\hline Frequency of scenario occurrence & & $\begin{array}{l}0.63(0.36) 0.17 \\
r^{2}=0.02\end{array}$ & & \\
\hline Frequency of scenario occurrence ${ }^{a}$ & & $\begin{array}{l}0.64(0.35) 0.18 \\
r^{2}=0.08^{*}\end{array}$ & & \\
\hline \multicolumn{5}{|l|}{ Intensity of depersonalization } \\
\hline Frequency of scenario occurrence & & $\begin{array}{l}0.64(0.47) 0.13 \\
r^{2}=0.01\end{array}$ & & \\
\hline Frequency of scenario occurrence ${ }^{a}$ & & $\begin{array}{l}0.68(0.48) 0.14 \\
r^{2}=0.01\end{array}$ & & \\
\hline \multicolumn{5}{|l|}{ Professional identity } \\
\hline Frequency of scenario occurrence & & & $\begin{array}{l}0.15(0.06) 0.20^{*} \\
r^{2}=0.03^{*}\end{array}$ & \\
\hline Frequency of scenario occurrence ${ }^{a}$ & & & $\begin{array}{l}0.14(0.07) 0.20 * \\
r^{2}=0.06\end{array}$ & \\
\hline
\end{tabular}

*P<0.05: ${ }^{* * P<0.01 ; * * * P<0.001 .}$

a Includes the following control variables: staff position, population of town worked, salary, race, clinical position and hours worked per week.

$r^{2}=$ Adjusted amount of variance explained. Unstd B, unstandardized beta; Std B, standardized beta. 


\section{Discussion}

The aim of this study was to explore the relationship between the various job-related scenarios and work-related outcomes, namely organizational commitment, professional commitment, job satisfaction, job burnout and professional identity. The scenarios which form the stressors in the study reflect the interplay between the type of encounters between pharmacists and physicians and demands on the job.

Respondents indicated that high-demand/pleasant encounters and low-demand/pleasant encounters occurred more frequently in the workplace than high-demand/ unpleasant encounters or low-demand/unpleasant encounters. Responses to the work-related attitudes show that overall the respondents indicated moderately high scores in the domains of affective commitment, continuance commitment and normative commitment: the three domains on the organizational commitment scale. This indicates that respondents had a moderately high level of organizational commitment. Further analysis also indicates moderately high levels of professional commitment, job satisfaction and professional identity. With respect to the job burnout inventory, respondents indicated that they felt emotionally exhausted but their level of personal accomplishment was moderately high and their level of depersonalization was low.

As hypothesized, low-demand/pleasant encounters were positively associated with feelings of personal accomplishment and professional identity and high-demand/unpleasant encounters were negatively associated with affective organizational commitment and positively associated with feelings of emotional exhaustion. Our analysis also indicated that, unexpectedly, the low-demand/unpleasant encounters were negatively associated with professional commitment and job satisfaction and positively associated with frequency of emotional exhaustion. On the other hand, high-demand/pleasant encounters were associated only with frequency and intensity of emotional exhaustion when demographic variables were held constant.

One strength of this study is that it represents the first investigation of the interplay between demands on the job and job-related resources in the form of interpersonal interactions using the JD-R model. Another strength is the use of actual practising pharmacists to provide information on the job demands and resources. Since the survey was sent out to pharmacists from a pre-existent list, we could not control whether all of the respondents had hospital-based experience or the extent to which the scenarios described actual work situations. The results suggest that most of the respondents indicated that these scenarios occurred. In addition, this was a cross-sectional study which may not represent causal relationships over time. Our response rate of 30\% limits the generalizability of the findings to other pharmacists and other practise settings, but is typical in studies of this type.
Repeating the study in various settings and in different countries would extend our findings. In addition, the amount of variance explained in the work-related outcomes was low to moderate. Other important variables may have been omitted from these analyses.

The findings of this study support evidence obtained in the literature in which job stress ${ }^{[13,18-23,34-37]}$ and interactions with healthcare professionals ${ }^{[4-8,12,38]}$ were found to affect work-related outcomes.

Based on the JD-R model, it was not surprising that highdemand/unpleasant encounters were negatively associated with affective organizational commitment or positively associated with emotional exhaustion, and low-demand/ pleasant encounters were positively correlated with feelings of personal accomplishment and professional identity. These results support the findings of previous research which indicates that job demands are related to exhaustion and low levels of resources are related to disengagement or lack of emotional attachment to the organization. ${ }^{[3]}$ This should be of concern to employers since decreased affective organizational commitment has been linked to job-turnover intention among pharmacists. ${ }^{[39]}$ On the other hand, when situations are positive (low demands or stress and high resources), feelings of personal accomplishment increase.

It is interesting to see how pharmacists respond to the interplay between demands on the job and interactions with physicians. Interaction with physicians has been found to be correlated with job satisfaction in pharmacists. ${ }^{[12]}$ This reflects the importance of interpersonal interactions in the workplace as suggested by a review of the literature. ${ }^{[5,12]}$ Thus, in our study, low demands in the workplace did not mitigate the effects of unpleasant encounters as expected. Instead, the frequency of occurrence of low-demand/unpleasant encounters negatively affected work-related outcomes for respondents in the study.

High-demand/pleasant encounters were only associated with emotional exhaustion, but not with the other workrelated outcomes. High demands, even with high resources, can lead to job burnout. Too much work can still lead to exhaustion. This finding is supported by a study of South African hospital pharmacists in which job demands were major stressors for these pharmacists. ${ }^{[40]}$ Another study found that workload issues had detrimental effects on morale and job satisfaction of newly qualified pharmacists in the UK. ${ }^{[41]}$

The effects of resources on work-related outcomes may be context-specific. ${ }^{[42]}$ Individuals facing high levels of stress may be more likely to use their resources as coping mechanisms. In this type of a scenario, although the pharmacists felt exhausted due to the high workload, a pleasant encounter seemed to have alleviated some of the effects on other work outcomes. The results of this study find support for the interaction effects in the JD-R model. Studies on Dutch workers found support for the interaction effects of various job 
demands and resources. ${ }^{[43,44]}$ In the current study unpleasant encounters appear to have negatively affected some workrelated outcomes irrespective of workload, and pleasant encounters seemed to alleviate to some extent the negative consequences of a heavy workload. It would be useful to extend this research to examine other types of job resource such as interactions with other pharmacists, nurses or healthcare managers and in other practice settings to determine whether similar results are obtained. Research outside of pharmacy indicates that jobs that are demanding need high levels of resources to lead to positive outcomes such as task enjoyment and organizational commitment. ${ }^{[44]}$ Interpersonal interactions could be one such resource.

\section{Conclusions}

These findings reveal an important aspect - namely interpersonal interaction in the healthcare workplace - which needs to be studied more extensively. Interpersonal interactions may be important to enhancing the work life of all health professionals. Given that pharmacists' workforce shortage and turnover continues to be an issue indicating that job demands would continue to increase, greater attention should be paid to the quality of interpersonal interactions as a means to improve the workplace environment. Pharmacy curricula should strive to include instruction on interpersonal interaction and communication with other healthcare professionals. This will help future healthcare professionals to deal with stressors and job demands more effectively and help to enhance their work life. Future research should focus on other types of job demands and resources specific to pharmacy.

\section{Declarations}

\section{Conflict of interest}

Anagha Nadkarni is an employee of Bristol-Myers Squibb, Co. This research was conducted when she was a graduate student at the University of Michigan.

\section{Funding}

This research was funded by the Upjohn Endowment Fund, College of Pharmacy, University of Michigan.

\section{References}

1. Pedersen CA etal. ASHP national survey of pharmacy practice in hospital settings: prescribing and transcribing 2009. Am J Health Syst Pharm 2009; 66: 926-946.

2. Hawthorne N, Anderson C. The global pharmacy workforce: a systematic review of the literature. Hum Resour Health 2009; 7: 48.

3. Demerouti E et al. The job demandsresources model of burnout. J Appl Psychol 2001; 86: 499-512.

4. Lindeke L, Sieckert A. Nurse-physician workplace collaboration. Online J Issues Nurs 2005; 10: manuscript 4.

5. Kramer M, Schmalenberg C. Securing 'good' nurse physician relationship. Nurs Manage 2003; 34: 34-38.

6. Grumbach K, Bodenheimer T. Can health care teams improve primary care practice? J Am Med Assoc 2004; 291: 1246-1251.

7. Larrabee $\mathrm{JH}$ et al. Predicting registered nurse job satisfaction and intent to leave. J Nurs Adm 2003; 33: 271283.

8. Rosenstein AH. Original research: nurse-physician relationships: impact on nurse satisfaction and retention. Am J Nurs 2002; 102: 26-34.

9. Zangaro GA, Soeken KL. A metaanalysis of studies of nurses' job satisfaction. Res Nurs Health 2007; 30: 445-458.

10. Rosenstein AH, O’Daniel M. Disruptive behavior and clinical outcomes: perceptions of nurses and physicians. Am J Nurs 2005; 105: 54-64.

11. Tabak N, Koprak O. Relationship between how nurses resolve their conflicts with doctors, their stress and job satisfaction. J Nurs Manag 2007; 15: 321-331.

12. Raisch DW. Barriers to providing cognitive services. Am Pharm 1993; NS33: 54-58.

13. Mott DA et al. Pharmacists' attitudes toward worklife: results from a national survey of pharmacists. J Am Pharm Assoc (Wash DC) 2004; 44: 326336.

14. Knapp DA. Professionally determined need for pharmacy services in 2020. Am J Pharm Educ 2002; 66: 421-429.

15. Hansen $\mathrm{N}$ et al. Predicting nurse burnout from demands and resources in three acute care hospitals under different forms of ownership: a cross- sectional questionnaire survey. Int $J$ Nurs Stud 2009; 46: 95-106.

16. Gaither CA et al. Should I stay or should I go? The influence of individual and organizational factors on pharmacists' future work plans. $J$ Am Pharm Assoc 2007; 47: 165-173.

17. Eckel FM, Caiola SM. Managing stress of the employee. In: Noel MW, Bootman JL, eds. Human Resource Management in Pharmacy Practice. Rockville, MD: Aspen Systems Corporation, 1983: 229-249.

18. Ortmeier BG, Wolfgang AP. Job related stress: perceptions of employee pharmacists. Am Pharm 1991; NS31: 27 31.

19. Wolfgang AP, Ortmeier BG. Career commitment, career plans, and jobrelated stress: a follow up study of pharmacy students as pharmacists. Am J Pharm Educ 1993; 57: 25-28.

20. Wolfgang AP et al. Job-related stress experienced by hospital pharmacists and nurses. Am J Hosp Pharm 1988; 45: 1342-1345.

21. Lahoz MR. Burnout among pharmacists: the influence of individual and job characteristics. $\mathrm{PhD}$ dissertation. Purdue University, 1987. 
22. Lahoz MR, Mason HL. Burnout among pharmacists. Am Pharm 1990; NS30: 28-32.

23. Mott DA. Pharmacist job turnover, length of service, and reasons for leaving, 1983-1997. Am J Health Syst Pharm 2000; 57: 975984.

24. Maslach C, Jackson SE. The measurement of experienced burnout. J Occup Behav 1981; 2: 99-113.

25. Meyer JP, Allen NJ. Testing the 'side-bet theory' of organizational commitment: some methodological considerations. J Appl Psychol 1984; 69: 372-378.

26. Meyer JP et al. Affective and continuance commitment to the organization: evaluation of measures and analysis of concurrent and time-lagged relations. J Appl Psychol 1990; 75: 710720.

27. Allen NJ, Meyer JP. The measurement and antecedents of affective, continuance and normative commitment to the organization. J Occup Psychol 1990; 63: 1-18.

28. Blau GJ. The measurement and prediction of career commitment. J Occup Psychol 1985; 58: 277288.

29. Blau GJ. Further exploring the meaning and measurement of career commitment. J Vocat Behav 1988; 32: 284-297.
30. Hackman JR, Oldham GR. Motivation through the design of work: test of a theory. Organ Behav Hum Perform 1976; 16: 250-279.

31. Bergami M, Bagozzi RP. Selfcategorization and commitment as distinct aspects of social identity in the organization: conceptualization, measurement, and relation to antecedents and consequences. Br J Soc Psychol 2000; 39: 555-577.

32. Maslach C, Jackson SE. Maslach Burnout Inventory Manual. Palo Alto, CA: Consulting Psychologists Press, Inc., 1986.

33. Armstrong JS, Overton TS. Estimating non-response bias in mail surveys. J Mark Res 1977; 14: 396-402.

34. Gaither CA. Career commitment: a mediator of the effects of job stress on pharmacists' work-related attitudes. JAm Pharm Assoc (Wash) 1999; 39:353361.

35. Gaither CA, Mason HL. A model of pharmacists' career commitment, organizational commitment, and career and job withdrawal intentions. $J$ Soc Adm Pharm 1992; 9: 75-86.

36. Gupchup GV, Worley-Louis MM. Understanding and managing stress among pharmacists. In: Desselle SP, Zgarrick DP, eds. Pharmacy Management: Essentials for All Practice Settings. New York: McGraw-Hill, 2005: 51-62.
37. Wolfgang AP. Job-Stress in the health professions: a study of physicians, nurses, and pharmacists. Behav Med 1988; 14: 43-47.

38. Cox ER, Fitzpatrick V. Pharmacists' job satisfaction and perceived utilization of skills. Am J Health Syst Pharm 1999; 56: 1733-1737.

39. Gaither CA et al. A modified model of pharmacists' job stress: the role of organizational, extra-role and individual factors on work-related outcomes. Res Social Adm Pharm 2008; 4: 231-243.

40. Rothmann S, Malan M. Occupational stress of hospital pharmacists in South Africa. Int J Pharm Pract 2007; 15: 235 242.

41. Eden $M$ et al. Workload pressure among recently qualified pharmacists: an exploratory study of intentions to leave the profession. Int J Pharm Pract 2009; 17: 181-187.

42. Hobfoll SE. Social and psychological resources and adaptation. Rev Gen Psychol 2002; 6: 307-324.

43. Bakker $\mathrm{AB}$ et al. Job resources buffer the impact of job demands on burnout. J Occup Health Psychol 2005; 10: 170180.

44. Bakker $\mathrm{AB}$ et al. Beyond the demandcontrol model: thriving on high job demands and resources. J Person Psychol 2010; 9: 3-16.

\section{APPENDIX A}

\section{Description of the stressors}

High demand: the high-demand scenario described a situation in which the pharmacist encounters a workday where the other pharmacist and technicians have called in sick, the hospital has a full census, many patients require complex therapies and the pharmacy is experimenting with a new computer system with which nobody is familiar.

Low demand: the low-demand scenario describes a situation in which the rest of the pharmacy staff - pharmacists as well as technicians - are in good spirits, the hospital census is steady, few patients require complex therapies and a new computer system is in place which has allowed for the workplace to run more smoothly.
Pleasant encounter: the pleasant encounter scenario describes a situation in which the pharmacist notices an allergy to a medication that has been prescribed by the physician. On paging the physician, he promptly returns the page, appreciates the thoroughness of the pharmacist, asks the pharmacist to recommend an alternative therapy and accepts the recommendation.

Unpleasant encounter: the unpleasant physician encounter scenario describes a situation in which the pharmacist notices an allergy to a medication that has been prescribed by the physician. On paging the physician, who is slow in returning the page, the physician is rude, tells the pharmacist not to second-guess his judgement and does not take the pharmacist's recommendation into account. 